\title{
Long-term outcome after mitral valve replacement using biological versus mechanical valves
}

\author{
Ayse Cetinkaya ${ }^{1}$, Julia Poggenpohl ${ }^{1}$, Karin Bramlage ${ }^{2}$, Stefan Hein ${ }^{1}$, Mirko Doss ${ }^{1}$, Peter Bramlage ${ }^{2^{*}}$ (D, \\ Markus Schönburg ${ }^{1}$ and Manfred Richter ${ }^{1}$
}

\begin{abstract}
Background: This study compared long-term outcomes of biological and mechanical mitral valve replacement (MVR) in patients requiring replacement of the mitral valve where repair was not feasible.

Methods: A single-centre registry of patients receiving MVR between 2005 and 2015 was established. Thirty-day mortality and long-term outcomes were analysed and compared.

Results: Three hundred twenty four patients underwent MVR (265 biological; 59 mechanical valves). Patients receiving biological valves were older $(p<0.001)$, had a higher log EuroSCORE $(p<0.001)$ and received less minimally invasive surgery $(p<0.001)$.

Immediate procedural mortality was $1.9 \%$, which only occurred in the biological valve group. At 30 days, $9.0 \%$ of patients had died, $4.0 \%$ experienced stroke, $8.0 \%$ received a pacemaker and $10.5 \%$ suffered an acute renal failure. The rate of re-thoracotomy (14.2\%) was lower in the biological (12.5\%) than in the mechanical valve group (22.0\%; adjOR $0.45[0.20-1.00] ; p=0.050)$. Frequent long-term complications were stroke (9.2\%) and bleeding (4.8\%), with bleeding complications being higher in the mechanical valve group $(p=0.009)$. During the follow-up period biological valves showed a numerically higher survival rate during the first years, which shifted after 3 years in favour of mechanical valves. At 10 years, survival rates were $62.4 \%$ vs. $77.1 \%$ in the biological and mechanical valve groups $(p=0.769)$. Hazard ratio after adjustment was 0.833 (95\% $\mathrm{Cl} 0.430-1.615)$.

Conclusion: These data confirm that mechanical valve implantation is associated with an increased risk of bleeding. While there was a potential survival benefit during the first years after surgery for patients receiving a biological valves the difference became insignificant after a follow-up of 10 years.
\end{abstract}

Keywords: Mitral valve replacement, Biological valve, Mechanical valve

\section{Background}

In accordance with guidelines from the European Society of Cardiology (ESC) and the European Association for Cardio-Thoracic Surgery (EACTS), mitral valve replacement (MVR) is a surgical procedure that is used when the patient's heart valve is so severely compromised that mitral valve (MV) repair is no longer a viable option [1, 2]. The American Heart Association (AHA) guidelines recommend MV surgery for asymptomatic

\footnotetext{
* Correspondence: peter.bramlage@ippmed.de

${ }^{2}$ Institute for Pharmacology and Preventive Medicine, Bahnhofstraße 20,

49661 Cloppenburg, Germany

Full list of author information is available at the end of the article
}

patients with chronic severe primary mitral regurgitation (MR) and left ventricular (LV) dysfunction [3, 4]. Again, MV repair is preferred over MVR when possible [3, 4].

Data on the choice of biological versus mechanical MV is controversial. Biological MVs are generally considered to be associated with lower bleeding complications due to the need for less or no anticoagulation, but they lack of durability. Mechanical valves are durable, but are associated with thromboembolism and bleeding complications mostly because of inevitable lifelong anticoagulation therapy $[2,5,6]$.

In a study of 279 patients undergoing MVR (154 biological and 125 mechanical valves), clinically satisfactory

(c) The Author(s). 2019 Open Access This article is distributed under the terms of the Creative Commons Attribution 4.0 International License (http://creativecommons.org/licenses/by/4.0/), which permits unrestricted use, distribution, and 
results were obtained in both groups. After 15 years, fewer patients in the mechanical valve group were free of bleeding events (92.5\% vs. $100 \%)$ and patients in the biological valve group had a lower freedom from thromboembolism $(72.2 \%$ vs. $93.5 \%)$, valve failure $(22.0 \%$ vs. $87.0 \%)$ and cardiac events (16.5\% vs. $47.2 \%)$. The study concluded that the use of mechanical valves was preferential and biological valves should be reserved for patients older than 65 years and only be used with concomitant anticoagulant therapy [5]. Conversely, the results of a 10-year follow-up study published in 2001 showed no significant clinical differences between patient groups receiving biological and mechanical valves [7]. These results confirm the findings of a study from the 1980s [8].

This paper aims to compare the outcomes after biological versus mechanical MVR in patients who were not suitable or ineligible for MV repair.

\section{Methods}

This study is a single-centre registry analysis of MVR procedures performed at the Kerckhoff-Heart Center, in Bad Nauheim, Germany, between January 2005 and December 2015. It was approved by the site's Ethical Committee and complied with the Declaration of Helsinki and its amendments. Given the use of anonymised data already collected as part of routine diagnosis and treatment, written informed consent was neither feasible nor required.

\section{Patient population}

All patients undergoing MVR at our site within the specified time period (January 2005-December 2015) were included. The study also included patients receiving MVR combined with tricuspid valve repair and ablation therapy, patent foramen ovale (PFO) or atrial septal defect (ASD) closure.

Age, comorbidity and lifestyle were considered when recommending biological valves to patients. Patients with a contraindication for vitamin $\mathrm{K}$ antagonists (VKA), women with a desire to become pregnant, certain professions (e.g., pilots) and those with a likely lack of compliance were also considered for biological valves even if they were less than 65 years of age.

Patients with endocarditis had their infection carefully resected. Patients with severe calcification and some of those with endocarditis received neochordae implanted at the mitral annulus. Patients with mitral insufficiency without calcification and without endocarditis who received MVR after two failed attempts had their anterior mitral leaflet (AML) resected and the posterior leaflet (PML) preserved to protect the subvalvular apparatus.

Exclusion criteria were a simultaneous coronary artery bypass grafting (CABG) or an aortic valve replacement. Of note, all patients with biological valves routinely receive acetylsalicylic acid (ASA) $100 \mathrm{mg}$ daily and patients with mechanical valves and/or atrial fibrillation received VKA.

\section{Data and outcomes}

In patients who had undergone an MVR, we checked electronic medical records (inpatient and outpatient notes and the results of any diagnostic testing). Clinical variables of interest were patient age, sex, comorbidity, prior cardiological interventions, echocardiography (pre-operative transthoracic echocardiogram [TTE], perioperative transoesophageal echocardiogram, one-week post-operative and upon follow-up) and relevant medical/surgical history. Follow-up data collected at the patient's last follow-up hospital or outpatient visit were valve-related complications and echocardiography parameters.

\section{Statistics}

Data were analysed using descriptive statistics, with categorical variables presented as absolute values and frequencies (\%) and normally distributed continuous variables as means with standard deviations (SDs). Nonnormally distributed continuous variables are presented as the median and interquartile range (IQR with the borders for the first and third quartile). Comparisons between biological and mechanical valve groups were carried out using a Student's T-test with Levine's homogeneity of variance or the Mann-Whitney U-test for continuous variables, as appropriate, and a Fisher's exact or Chi-square test for categorical variables. For outcome analyses odds ratios (OR) were calculated by logistic regression. Survival analysis was presented as KaplanMeier (KM) curve. Hazard ratios (HR) were calculated by Cox-regression and adjusted for major baseline variables. Freedom from major complications (embolism/ stroke and bleeding) were displayed as KM curves. For patients without a documented time-point for the documented event (embolism/stroke or bleeding), the time to death or the time of the last follow-up visit was used and divided by two for the KM curves. In all cases, a two-tailed $P$-value of $<0.05$ was considered statistically significant. All statistical tests were performed using IBM SPSS Statistics software version 24.0 (Armonk, NY. IBM Corporation).

\section{Results}

Between 2005 and 2015, 1357 patients received MV surgery at the Kerckhoff-Heart Center, including 324 patients receiving MVR. Of these patients, 265 patients received a biological valve and 59 a mechanical valve (Fig. 1). 


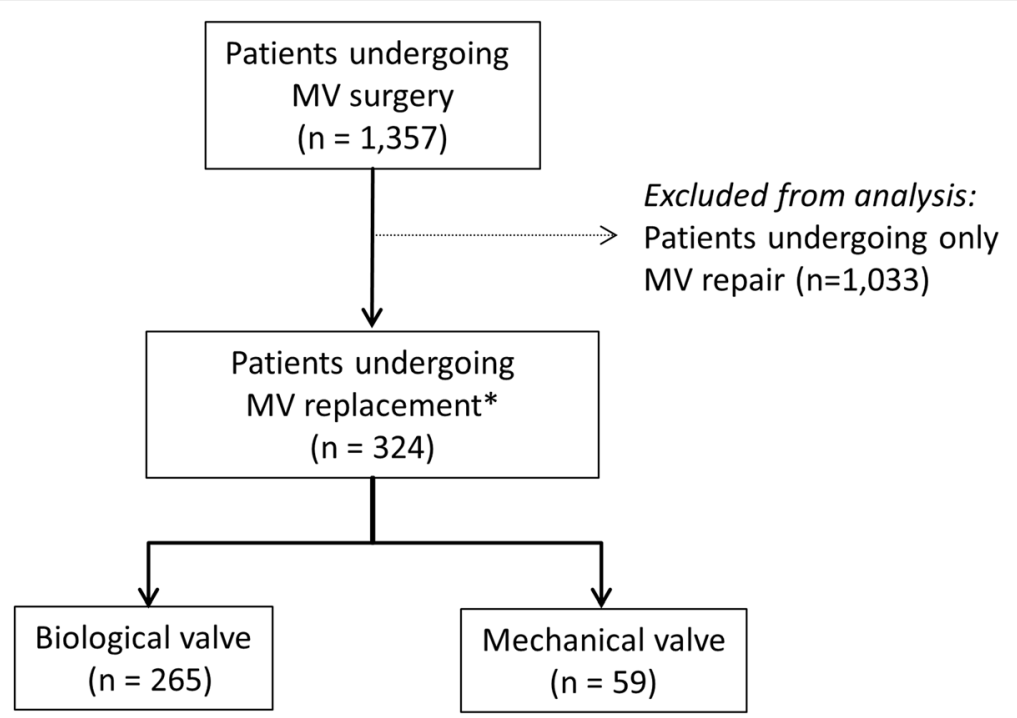

Fig. 1 Flow Chart. Legend: MV, mitral valve. ${ }^{*} 123$ patients underwent MV replacement after a MV repair was attempted

\section{Patient characteristics}

Patient characteristics, MV pathologies and echocardiographic parameters are presented in Tables 1 and 2. Overall, $49.7 \%$ of patients were female and $38.9 \%$ had atrial fibrillation. The majority of patients had degenerative MV disease (96.0\%) with a dilated annulus (71.3\%) and MV insufficiency grade $\geq$ II (96.6\%). $28.7 \%$ of the patients presented with MV stenosis and $14.5 \%$ suffered from acute endocarditis. Patients receiving biological valves were older (71.0 vs. 56.0 years; $p<0.001)$ and had a significantly higher median log EuroSCORE I (8.4\% vs. $4.5 \% ; p<0.001)$.

\section{Procedural details and outcomes}

Patients in the biological valve group received less minimally invasive MV surgery (MIC; $37.4 \%$ vs. $61.0 \%$; $p=0.001$ ) and more conventional sternotomy (CS) (Table 3). While the operating time was comparable between the two groups there was a shorter cardiopulmonary bypass (CPB) time in the biological valve group $(p=0.030)$. Hospital stay was lower in the biological valve group (Table 3) $(p=0.012)$. Noteworthy was a higher need for secondary MV repair (11.9 vs. $0.8 \% ; p<0.001)$ in the mechanical valve group.

Frequent procedure related complications after MVR were atrial fibrillation (21.0\%) and pneumonia (9.9\%) (Table 4). There were no statistically significant differences between groups. Immediate procedural mortality (1.9\%) was only seen in patients undergoing biological valve replacement.

\section{Echocardiography data}

The mean post-operative diastolic MV gradient was 5.0 $\mathrm{mmHg}$ for all patients and patients receiving a biological valve, but $4.0 \mathrm{mmHg}$ for patients receiving mechanical valves $(p=0.833)$. After a mean follow-up of 6.4 years, the difference between the groups became significant ( $p=0.018)$. The recorded peak diastolic MV gradient was $13.0 \mathrm{mmHg}$ in the biological valve group and 9.5 $\mathrm{mmHg}$ in the mechanical valve group $(p=0.117)$, after a mean follow-up of 5.7 years.

\section{Follow-up}

At 30 days, $9.0 \%$ of all patients had died, $4.0 \%$ experienced stroke, $10.5 \%$ acute renal failure, $8.0 \%$ received a pacemaker and $14.2 \%$ had to undergo re-thoracotomy (Table 5). OR between groups were, however, not statistically different for either the unadjusted and adjusted analyses. Re-thoracotomies had the highest absolute difference of $9.5 \%$ (12.5\% vs. 22.0\%; adjusted OR 0.45, 95\% CI $0.20-1.00 ; p=0.050)$.

The most frequent major complication was embolism, which occurred in $9.2 \%(19 / 229)$ of patients $(9.2 \%$ [17/184] vs. $4.4 \%$ [2/45] in the biological and mechanical valve groups, respectively; $p=0.381$ ) and mostly affected the brain. Bleeding complications occurred in $4.8 \%(11 / 229)$ of patients, but were significantly higher in the mechanical valve group $(13.3 \%$ [6/45] vs. $2.7 \%$ [5/184], respectively; $p=0.009$ ) (Additional file 1 : Table S1). In Additional file 2: Figure S1 the occurrences of these two complications over time are shown as KM curves.

In the overall follow-up period of up to 10 years, we found that during the first post-treatment years patients receiving a biological MV had a nominally better survival rate. 3 years post-treatment, this shifted nominally in favour of patients receiving mechanical valves. Survival rates were $62.4 \%$ for biological and $77.1 \%$ for 
Table 1 Patient characteristics

\begin{tabular}{|c|c|c|c|c|}
\hline & $\begin{array}{l}\text { Total } \\
N=324\end{array}$ & $\begin{array}{l}\text { Biological MVR } \\
N=265\end{array}$ & $\begin{array}{l}\text { Mechanical MVR } \\
N=59\end{array}$ & $p$-value \\
\hline Age in years & $69.0[58.0-76.0][324]$ & $71.0[62.0-77.0][265]$ & $56.0[50.0-62.0][59]$ & $<0.001$ \\
\hline$\leq 65$ years, $\%$ & $133 / 324(41.0)$ & $86 / 265(32.5)$ & $47 / 59(79.7)$ & $<0.001$ \\
\hline Female gender, $\%$ & $161 / 324(49.7)$ & $137 / 265(51.7)$ & $24 / 59(40.7)$ & 0.126 \\
\hline $\mathrm{BMI}\left(\mathrm{kg} / \mathrm{m}^{2}\right)$ & $26.2[23.2-29.0][256]$ & $26.2[23.0-28.9][214]$ & $26.9[23.2-31.7][42]$ & 0.337 \\
\hline \multicolumn{5}{|l|}{ CV risk factors } \\
\hline Hypertension, \% & $173 / 324(53.4)$ & $147 / 265(55.5)$ & $26 / 59(44.1)$ & 0.112 \\
\hline Dyslipidemia, \% & $52 / 324(16.0)$ & 46/265 (17.4) & $6 / 59(10.2)$ & 0.174 \\
\hline \multicolumn{5}{|l|}{ Comorbidity general } \\
\hline Diabetes mellitus, \% & $35 / 324(10.8)$ & $31 / 265(11.7)$ & $4 / 59(6.8)$ & 0.271 \\
\hline Kidney failure (Crea. > 2.26 mg/dL) & $8 / 324(2.5)$ & $7 / 265(2.6)$ & $1 / 59(1.7)$ & 1.000 \\
\hline Stroke, \% & $30 / 324(9.3)$ & $27 / 265(10.2)$ & $3 / 59(5.1)$ & 0.221 \\
\hline COPD, \% & $44 / 324(13.6)$ & $39 / 265(14.7)$ & $5 / 59(8.5)$ & 0.206 \\
\hline$P A D, \%$ & $17 / 324(5.2)$ & $16 / 265(6.0)$ & $1 / 59(1.7)$ & 0.328 \\
\hline \multicolumn{5}{|l|}{ Comorbidity cardiac } \\
\hline Atrial fibrillation, \% & 126/324 (38.9) & 102/265 (38.5) & $24 / 59(40.7)$ & 0.755 \\
\hline Coronary artery disease, $\%$ & 45/324 (13.9) & $41 / 265(15.5)$ & $4 / 59(6.8)$ & 0.081 \\
\hline Prior MI ( $\leq 90$ days), $\%$ & $4 / 324(1.2)$ & $3 / 265(1.1)$ & $1 / 59(1.7)$ & 0.554 \\
\hline Prior aortic valve replacement, $\%$ & 15/324 (4.6) & $11 / 265(4.2)$ & $4 / 59(6.8)$ & 0.489 \\
\hline Prior CABG, \% & $25 / 324(7.7)$ & $23 / 265(8.7)$ & $2 / 59(3.4)$ & 0.277 \\
\hline Prior pacemaker, \% & $13 / 324(4.0)$ & $11 / 265(4.2)$ & $2 / 59(3.4)$ & 1.000 \\
\hline NYHA class III/IV, \% & $273 / 324(84.3)$ & 225/265 (84.9) & $48 / 59(81.4)$ & 0.498 \\
\hline CCS class III $\%^{a}$ & 16/324 (4.9) & $12 / 265(4.5)$ & $4 / 59(6.8)$ & 0.505 \\
\hline Pulmonary hypertension, \% & $56 / 324(17.3)$ & $47 / 265(17.7)$ & $9 / 59(15.3)$ & 0.648 \\
\hline Emergency indication for surgery, \% & $31 / 324(9.6)$ & 23/265 (8.7) & 8/59 (13.6) & 0.249 \\
\hline Cardiac decompensation, \% & $112 / 324(34.6)$ & 95/265 (35.8) & $17 / 59(28.8)$ & 0.304 \\
\hline Log EuroSCORE I (\%) & $7.2[3.5-15.6][322]$ & $8.4[3.6-17.5][263]$ & $4.5[2.9-8.0][59]$ & $<0.001$ \\
\hline
\end{tabular}

Legend: Values are patients applicable/patients with available information with percentage in brackets OR medians with IQR in brackets and available patient number in brackets; ${ }^{a}$ No patient presented with CCS class IV in this collective

$B M I$ body mass index, $C V$ cardiovascular, CABG coronary artery bypass graft, CCS Canadian Cardiovascular Society, COPD chronic obstructive pulmonary disease, MI myocardial infarction, NYHA,New York Heart Association, PAD peripheral artery disease, SD standard deviation

mechanical valves at 10 years $(p=0.769)$. Differences were not statistically significant at any time point (Fig. 2) . The HR was 1.264 (95\% CI 0.687-2.325; $p=0.451$ ). After adjustment for key baseline variables (age, CAD, MV regurgitation grade $\geq \mathrm{II}$, logistic EuroScore-I) no significant statistical difference between biological and mechanical valves was found (HR 0.833 (95\% CI 0.430$1.615) ; p=0.589$ ).

\section{Discussion}

This single centre study provides a contemporary picture of the safety and effectiveness of the two valve concepts. Event rates at 30 days may appear slightly high and we consider this the result of our clinic getting referrals of very complex cases that may result in longer procedural times and hazards. Furthermore our clinic is frequently chosen for re-interventions after failed procedures. Our study revealed a success rate of MVR that is quite comparable between valves, but confirmed that biological valves were used in older patients, while mechanical valves were used in younger patients and associated with an increased risk of bleeding.

Both types of valves have advantages and disadvantages, but also specific patient factors need to be taken into consideration when making the decision on which valve type to use $[9,10]$. Historically, biological MVs were generally considered to have superior antithrombotic properties but lacked durability, while mechanical valves were thought to be more durable but were associated with thromboembolism and bleeding events $[2,5,6,9]$. The data from our study confirm the observation that the use of anticoagulation along with mechanical valve implantation is associated with an increased risk of bleeding and that there is a potential survival benefit for patients receiving a biological MV. 
Table 2 MV pathologies and echocardiographic parameters

\begin{tabular}{|c|c|c|c|c|}
\hline & $\begin{array}{l}\text { Total } \\
N=324\end{array}$ & $\begin{array}{l}\text { Biological MVR } \\
N=265\end{array}$ & $\begin{array}{l}\text { Mechanical MVR } \\
N=59\end{array}$ & $p$-value \\
\hline MV pathologies & & & & 0.712 \\
\hline Functional, \% & 13/324 (4.0) & 10/265 (3.8) & $3 / 59(5.1)$ & \\
\hline Degenerative, \% & $311 / 324(96.0)$ & $255 / 265(96.2)$ & $56 / 59(94.9)$ & \\
\hline Acute endocarditis, \% & $47 / 324(14.5)$ & $37 / 265(14.0)$ & 10/59 (16.9) & 0.556 \\
\hline MV stenosis, \% & $93 / 324(28.7)$ & $71 / 265(26.8)$ & $22 / 59(37.3)$ & 0.107 \\
\hline Annulus dilatation, $\%$ & 231/324 (71.3) & 189/265 (71.3) & $42 / 59(71.2)$ & 0.984 \\
\hline Annulus calcification, \% & $91 / 324(28.1)$ & $72 / 265(27.2)$ & 19/59 (32.2) & 0.437 \\
\hline AML prolapse, $\%$ & $78 / 324(24.1)$ & $69 / 265(23.0)$ & 17/59 (28.8) & 0.346 \\
\hline AML flail, \% & $35 / 324(10.8)$ & 27/265 (10.2) & $8 / 59(13.6)$ & 0.395 \\
\hline PML prolapse, $\%$ & $119 / 324(36.7)$ & $99 / 265(37.4)$ & 20/59 (33.9) & 0.618 \\
\hline PML flail, \% & 83/324 (25.6) & $72 / 265(27.2)$ & 11/59 (18.6) & 0.175 \\
\hline Chordae elongation, \% & $54 / 324(16.7)$ & $42 / 265(15.8)$ & $12 / 59(20.3)$ & 0.403 \\
\hline Restrictive leaflet, \% & $157 / 324(48.5)$ & $126 / 265(47.5)$ & $31 / 59(52.5)$ & 0.487 \\
\hline MV insuff. Grade $\geq \|^{a}, \%$ & 313/324 (96.6) & $260 / 265(98.1)$ & $53 / 59(89.8)$ & 0.006 \\
\hline \multicolumn{5}{|c|}{ Echocardiographic parameters } \\
\hline LVEF, \% & $56.0[50.0-60.0][324]$ & $58.0[50.0-60.0][265]$ & 55.0 [48.3-60.0] [59] & 0.292 \\
\hline LVEDD (mm) & 54.0 [49.0-59.0] [214] & 54.0 [49.0-59.0] [200] & 54.0 [50.0-57.0] [49] & 0.950 \\
\hline $\operatorname{LVESD}(\mathrm{mm})$ & $35.0[31.0-40.5][237]$ & 35.0 [31.0-41.0] [191] & 35.0 [32.0-40.0] [46] & 0.444 \\
\hline Left atrium (mm) & $55.0 \pm 10.5[251]$ & $54.5 \pm 10.2[203]$ & $57.2 \pm 11.9[48]$ & 0.107 \\
\hline Right atrium (mm) & $45.0[38.0-53.0][251]$ & 45.0 [38.0-53.0] [203] & $48.5[39.3-54.5][48]$ & 0.318 \\
\hline Mitral opening (mm) & $3.4 \pm 1.8[93]$ & $3.4 \pm 1.6[79]$ & $3.3 \pm 2.6[14]$ & 0.966 \\
\hline PISA radius (mm) & $1.0[1.0-1.2][56]$ & $1.0[1.0-1.2][46]$ & 1.0 [0.9-1.1] [10] & 0.426 \\
\hline Vena contracta $(\mathrm{mm})$ & $6.0[5.0-7.0][90]$ & $6.0[4.0-7.0][78]$ & 6.0 [5.0-7.0] [12] & 0.717 \\
\hline
\end{tabular}

Legend: Values are patients applicable/patients with available information with percentage in brackets OR means \pm SD with available patient numbers in brackets OR medians with IQR in brackets and available patient number in brackets; ${ }^{\text {a }}$ patients with MR grade $<$ II initially underwent mitral valve repair and, in cases where the result was not satisfactory, underwent mitral valve replacement

$A M L$ anterior mitral valve leaflet, $L V E D D$ left ventricular end diastolic pressure, $L V E F$ left ventricular ejection fraction, $L V E S D$ left ventricular end systolic pressure, $M V$ mitral valve, PISA proximal isovelocity surface area, $P M L$ posterior mitral valve leaflet, $S D$ standard deviation

Earlier studies report that mechanical valves were associated with increased durability $[2,5,6]$. The KM data confirm that at 10 years patient survival is higher with the mechanical valve than the biological valve $(77.1 \%$ vs. $62.4 \%$, respectively), despite survival being nominally higher with the biological valve within the first years of follow-up. Our Cox regression analysis revealed that after adjustment for key baseline variables there was no significant difference between the two valve types (HR 0.833 ; $95 \%$ CI $0.430-1.615 ; p=0.589$ ). Further information is needed to determine if the durability of the mechanical and biological valve affects patient survival because the biological valve recipients were 15 years older in our dataset. In addition, biological valves have been associated with an increased risk of re-operation and structural valve deterioration, which may start to occur at 3 years but, on the other hand, a durability of 12-plus years has also been reported [11-15].
Patient-specific factors, including age, surgical factors, comorbidities and patient preference, also influence the choice of valve type $[9,16]$. With respect to the patient's age, the general recommendations are that patients younger than 65 years should receive a mechanical valve because of their increased durability, while patients older than 65 years should be considered for a biological valve, as they are less likely to outlive the valve's life expectancy $[9,17,18]$. Our study mirrors this approach, with the median age of patients in the mechanical valve group being 15 years lower. Comorbidities, such as atrial fibrillation, renal failure and diabetes, and surgical factors, such as the need for concurrent aortic root replacement, also affect valve selection $[9,19]$, although we did not observe any statistically significant difference in the rate of these comorbidities.

In the future, improvements in mechanical valve structure may lower the risk of thromboembolism 
Table 3 Procedural details

\begin{tabular}{|c|c|c|c|c|}
\hline & $\begin{array}{l}\text { Total } \\
N=324\end{array}$ & $\begin{array}{l}\text { Biological MVR } \\
N=265\end{array}$ & $\begin{array}{l}\text { Mechanical MVR } \\
N=59\end{array}$ & $p$-value \\
\hline Operative approach & & & & 0.001 \\
\hline MIC, \% & $135 / 324(41.7)$ & 99/265 (37.4) & $36 / 59(61.0)$ & \\
\hline $\mathrm{CS}, \%$ & 189/324 (58.3) & 166/265 (62.6) & 23/59 (39.0) & \\
\hline MV size & & & & 0.652 \\
\hline $25 \mathrm{~mm}, \%$ & 2/324 (0.6) & $2 / 265(0.8)$ & - & \\
\hline $26 \mathrm{~mm}, \%$ & $1 / 324(0.3)$ & $1 / 265(0.4)$ & - & \\
\hline $27 \mathrm{~mm}, \%$ & 45/324 (13.9) & $40 / 265(15.1)$ & $5 / 59(8.5)$ & \\
\hline $29 \mathrm{~mm}, \%$ & 99/324 (30.6) & 82/265 (30.9) & 17/59 (28.8) & \\
\hline $31 \mathrm{~mm}, \%$ & $128 / 324(39.5)$ & 100/265 (37.7) & $28 / 59(47.5)$ & \\
\hline $33 \mathrm{~mm}, \%$ & 49/324 (15.1) & 40/265 (15.1) & $9 / 59(15.3)$ & \\
\hline \multicolumn{5}{|l|}{ Times } \\
\hline Procedure time (min) & 196.5 [166.3-240.0] [324] & 197.0 [165.5-239.0] [265] & 192.0 [170.0-258.0] [59] & 0.539 \\
\hline CPB time (min) & 117.0 [166.3-146.8] [324] & 114.0 [94.0-145.0] [265] & 126.0 [105.0-154.0] [59] & 0.030 \\
\hline x-clamp time (min) & 72.0 [59.0-92.8] [324] & 71.0 [58.0-91.0] [265] & 74.0 [62.0-99.0] [59] & 0.235 \\
\hline Length of intubation (h) & 12.0 [9.0-18.0] [324] & 12.0 [9.0-18.0] [265] & 11.0 [8.0-17.0] [59] & 0.230 \\
\hline Length of ICU (h) & 34.5 [22.0-75.8] [324] & 34.0 [22.0-72.0] [265] & 47.0 [23.0-108.0] [59] & 0.095 \\
\hline Length of hospital stay (d) & $12.0[9.0-17.0][324]$ & 11.0 [9.0-17.0] [265] & 14.0 [11.0-19.0] [59] & 0.012 \\
\hline \multicolumn{5}{|l|}{ Concomitant procedures } \\
\hline Cryo ablation, \% & $82 / 323(25.4)$ & $65 / 265(24.5)$ & 17/58 (29.3) & 0.448 \\
\hline LAA closure, \% & $88 / 324(27.2)$ & $74 / 265(27.9)$ & $14 / 59(23.7)$ & 0.512 \\
\hline Tricuspid valve repair, \% & 63/323 (19.5) & $53 / 264(20.1)$ & 10/59 (16.9) & 0.584 \\
\hline PFO closure, \% & 13/324 (4.0) & 10/265 (3.8) & $3 / 59(5.1)$ & 0.712 \\
\hline ASD closure, $\%$ & 6/324 (1.9) & $5 / 265(1.9)$ & $1 / 59(1.7)$ & 1.000 \\
\hline Second MV repair, \% & 9/324 (2.8) & 2/265 (0.8) & $7 / 59(11.9)$ & $<0.001$ \\
\hline Conversion to $\mathrm{CS}^{\mathrm{a}}, \%$ & 9/137 (6.6) & 9/101 (8.9) & $0 / 36(0)$ & 0.112 \\
\hline
\end{tabular}

Legend: Values are patients applicable/patients with available information with percentage in brackets OR medians with IQR in brackets and available patient number in brackets; ${ }^{\text {}}$ Reasons for conversion were severe forms of trichterbrust, severely elevated diaphragm or severe adhesion of the right pleura, as well as severe intraoperative bleeding

$A S D$ atrial septum defect, $C P B$ cardiopulmonary bypass, $C S$ conventional sternotomy, ICU intensive care unit, $L A A$ left atrial appendage, $M I C$ minimally invasive mitral valve surgery, $M V$ mitral valve, $P F O$ patent foramen ovale, $S D$ standard deviation

Table 4 Procedure-related complications

\begin{tabular}{lllll}
\hline & $\begin{array}{l}\text { Biological MVR } \\
N=265\end{array}$ & $\begin{array}{l}\text { Mechanical MVR } \\
N=59\end{array}$ & $\begin{array}{l}\text { Odds Ratio } \\
95 \% \text { Cl }\end{array}$ & $\begin{array}{l}\text { Adjusted Odds Ratio } \\
95 \% \mathrm{Cl}\end{array}$ \\
\hline Wound infection, \% & $9 / 265(3.4)$ & $1 / 59(1.7)$ & $2.04(0.25-16.41)$ & $1.01(0.11-9.77)$ \\
Pericardial tamponade, \% & $21 / 265(7.9)$ & $5 / 59(8.5)$ & $0.93(0.34-2.58)$ & $0.67(0.22-2.05)$ \\
AV block grade III, \% & $22 / 265(8.3)$ & $5 / 59(8.5)$ & $0.98(0.35-2.70)$ & $0.57(0.18-1.75)$ \\
Pneumonia, \% & $27 / 265(10.2)$ & $5 / 59(8.5)$ & $1.23(0.45-3.33)$ & $1.02(0.35-2.97)$ \\
Pneumothorax, \% & $2 / 265(0.8)$ & $2 / 59(3.4)$ & $0.22(0.03-1.57)$ & $0.22(0.02-1.98)$ \\
Pleural effusion, \% & $12 / 265(4.5)$ & $1 / 59(1.7)$ & $1.59(0.19-13.44)$ & $1.62(0.18-14.45)$ \\
Atrial fibrillation, \% & $59 / 265(22.3)$ & $9 / 59(15.3)$ & $1.60(0.74-3.44)$ & $1.09(0.47-2.51)$ \\
MVI $\geq$ II post OP, \% & $6 / 264(2.3)$ & $1 / 59(1.7)$ & $1.35(0.16-11.42)$ & $1.86(0.20-17.31)$ \\
Immediate 72 h procedural mortality, \% & $6 / 265(2.3)$ & $0 / 59(0)$ & n.a. & n.a. \\
\hline
\end{tabular}

Legend: Values are patients applicable/patients with available information with percentage in brackets

AV atrioventricular, MVI mitral valve insufficiency, n.a. not applicable

${ }^{a}$ Odds Ratios were calculated by logistic regression and adjusted for age, logistic EuroScore -I, CAD and MV insuff. Grade $\geq$ II (preOP) 
Table 5 30-day Outcomes

\begin{tabular}{|c|c|c|c|c|}
\hline & $\begin{array}{l}\text { Biological MVR } \\
N=265\end{array}$ & $\begin{array}{l}\text { Mechanical MVR } \\
N=59\end{array}$ & $\begin{array}{l}\text { Odds Ratio } \\
95 \% \mathrm{Cl}\end{array}$ & $\begin{array}{l}\text { Adjusted Odds Ratio } \\
95 \% \mathrm{Cl}\end{array}$ \\
\hline Death, \% & $23 / 265(8.7)$ & $6 / 59(10.2)$ & $0.84(0.33-2.16)$ & $0.50(0.17-1.52)$ \\
\hline Cardiac death, \% & $15 / 265(5.7)$ & 4/59 (6.8) & $0.88(0.28-2.75)$ & $0.66(0.18-2.42)$ \\
\hline Non-cardiac death, $\%$ & $8 / 265(3.0)$ & 2/59 (3.4) & $0.89(0.18-4.29)$ & $0.37(0.06-2.32)$ \\
\hline Stroke, \% & $11 / 265(4.2)$ & 2/59 (3.4) & $1.23(0.27-5.72)$ & $0.47(0.08-2.66)$ \\
\hline Acute renal failure, $\%$ & $27 / 265(10.2)$ & $7 / 59(11.9)$ & $0.85(0.35-2.05)$ & $0.45(0.16-1.24)$ \\
\hline Myocardial infarction, \% & 0/265 (0) & 2/59 (3.4) & n.a. & n.a. \\
\hline Pacemaker implantation, \% & 20/264 (7.6) & $6 / 59(10.2)$ & $0.45(0.16-1.29)$ & $0.72(0.28-1.89)$ \\
\hline Re-thoracotomy, \% & $33 / 265$ (12.5) & 13/59 (22.0) & $0.50(0.25-1.03)$ & $0.45(0.20-1.00)$ \\
\hline
\end{tabular}

Legend: Values are patients applicable/patients with available information with percentage in brackets

n.a. not applicable

${ }^{\mathrm{a}}$ Odds ratios were calculated by logistic regression and adjusted for age, logistic EuroScore-I, CAD and MV insuff. $\geq$ grade II (preOP)

thus potentially reducing the intensity of lifelong anticoagulation, which may result in a preference for these valve types [20]. Furthermore, newer oral anticoagulants may also make mechanical valves more attractive from both the patient's perspective and from a medical standpoint [21].

\section{Limitations}

Overall, 324 patients were included in this study. The majority of these study patients received a biological valve $(n=265)$ and only 59 patients received a mechanical valve. Furthermore, patients receiving mechanical valve were typically younger than those receiving biological valve. Finally, there is an evolution of surgical techniques over time. As such, we adjusted the outcomes for differences in baseline variables to overcome this limitation. Data on major complications and echo data, collected at the patient's last follow-up visit, were not available for some patients as they only recently received their implant. The data, however, provide a useful insight into post-procedural major complications and echocardiographic data.

\section{Conclusions}

Despite a significant passage of time since MVR was first performed, many of the findings remain the same - biological valves tend to be implanted in older patients while mechanical valves are preferred in younger patients but associated with a higher risk of bleeding. The estimated 10-year survival rate tended to be higher in patients receiving mechanical valves; but adjusted Cox regression analysis showed no significant difference between the two valve types. It appears, therefore, as if valve selection may not be as important for patient survival as prior data suggested.

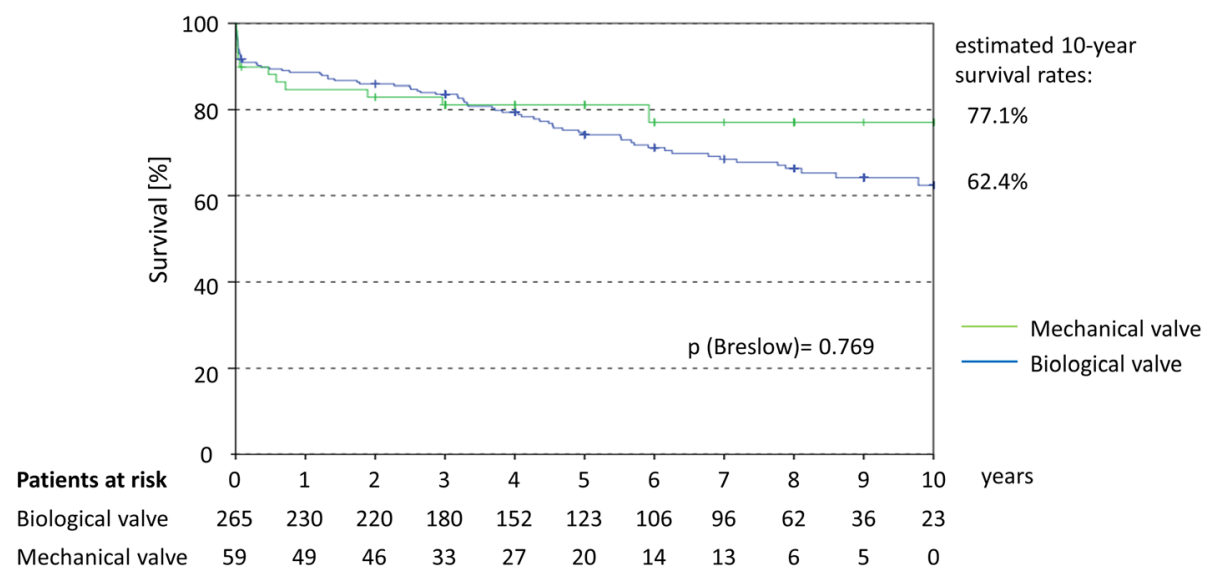

Fig. 2 Kaplan-Meier curve for the long-term survival after MVR. Legend: HR calculated by COX regression was $1.264(95 \%$ Cl 0.687-2.325; $p=0.451)$ After adjustment for age, logistic EuroScore-I, CAD and MV regurgitation grade $\geq \|$ (preOP) the HR was $0.833(95 \% \mathrm{Cl} 0.430-1.615 ; p=0.589)$ in favour for biological valves 


\section{Additional files}

Additional file 1: Table S1. Major complications (embolism/stroke and bleeding) and their localisation. Legend: Values are patients applicable/ patients with available information with the percentage in brackets. MI, myocardial infarction. (DOCX $12 \mathrm{~kb}$ )

Additional file 2: Figure S1. Kaplan-Meier curves for embolism/stroke (A) and bleeding (B) complications. (TIF $1692 \mathrm{~kb}$ )

\section{Abbreviations}

adj: Adjusted; AHA: American Heart Association; AML: Anterior mitral valve leaflet; ASA: Acetylsalicylic acid; ASD: Atrial septal defect; BMI: Body mass index; CABG: Coronary artery bypass grafting; CAD: Coronary artery disease; CCS: Canadian Cardiovascular Society; COPD: Chronic obstructive pulmonary disease: CPB: Cardio-pulmonary bypass; CS: Conventional sternotomy; CV: Cardiovascular; EACTS: European Association for Cardio-Thoracic Surgery; ESC: European Society of Cardiology; HR: Hazard ratio; ICU: intensive care unit: IQR: Interquartile range; KM: Kaplan-Meier; LAA: Left atrial appendage; LV: Left ventricular; LVEDD : Left ventricular enddiastolic pressure; LVEF: Left ventricular ejection fraction; LVESD: Left ventricular endsystolic pressure; MI: Myocardial infarction; MV: Mitral valve; MVI: Mitral valve insufficiency; MVR: Mitral valve replacement; MVRep: Mitral valve repair; NYHA: New York Heart Association; OR: Odds ratio; PAD: Peripheal artery disease; PFO: Patent foramen ovale; PISA: Proximal isovelocity surface area; PML: Posterior mitral valve leaflet; SD: Standard deviation; TEE: Transoesophageal echocardiography

\section{Acknowledgements}

Not applicable.

\section{Authors' contributions}

$A C, S H, M S, M D$ and MR performed the surgery and collected the data. AC, KB, $\mathrm{PB}$ and JP worked on the datset, designed the analyses and developed the concept of the paper. AC and PB drafted the manuscript which was critically revised by $\mathrm{SH}, \mathrm{KB}, \mathrm{MS}, \mathrm{MD}, \mathrm{JP}$ and $\mathrm{MR}$. All authors approved the final version of the manuscript and can be held accountable for the integrity of the work

\section{Funding}

This work was supported by funding from Edwards Lifesciences.

\section{Availability of data and materials}

The datasets used and analysed during the current study are available from the corresponding author on reasonable request.

\section{Ethics approval and consent to participate}

This study was approved by the site's Ethical Committee and complied with the Declaration of Helsinki and its amendments. Given the use of anonymised data already collected as part of routine diagnosis and treatment, written informed consent was neither feasible nor required.

\section{Consent for publication}

Not applicable.

\section{Competing interests}

Peter Bramlage received research funding from Edwards Lifesciences related and unrelated to the present work. The other authors have no conflict of interest to disclose.

\section{Author details}

${ }^{1}$ Department of Cardiac Surgery, Kerckhoff-Heart Center Bad Nauheim, 61231 Bad Nauheim, Germany. ${ }^{2}$ Institute for Pharmacology and Preventive Medicine, Bahnhofstraße 20, 49661 Cloppenburg, Germany.

Received: 27 March 2019 Accepted: 17 June 2019

Published online: 28 June 2019

\section{References}

1. Ribeiro AH, Wender OC, de Almeida AS, Soares LE, Picon PD. Comparison of clinical outcomes in patients undergoing mitral valve replacement with mechanical or biological substitutes: a 20 years cohort. BMC Cardiovasc Disord. 2014;14:146.
2. Baumgartner H, Falk V, Bax JJ, De Bonis M, Hamm C, Holm PJ, et al. 2017 ESC/EACTS guidelines for the management of valvular heart disease. Eur Heart J. 2017;38:2739-91.

3. Nishimura RA, Otto CM, Bonow RO, Carabello BA, Erwin JP 3rd, Guyton RA, et al. 2014 AHA/ACC guideline for the Management of Patients with Valvular Heart Disease: a report of the American College of Cardiology/American Heart Association task force on practice guidelines. Circulation. 2014;129:e521-643.

4. Nishimura RA, Otto CM, Bonow RO, Carabello BA, Erwin JP 3rd, Fleisher LA, et al. AHA/ACC Focused Update of the 2014 AHA/ACC Guideline for the Management of Patients With Valvular Heart Disease: A Report of the American College of Cardiology/American Heart Association Task Force on Clinical Practice Guidelines. Circulation. 2017;135:e1159-e95.

5. Yao H, Miyamoto T, Mukai S, Yamamura M, Tanaka H, Nakagawa T, et al. Long-term results of mitral valve replacement: biological xenograft versus mechanical valves. J Artif Organs. 2003:6:30-6.

6. lung B, Rodes-Cabau J. The optimal management of anti-thrombotic therapy after valve replacement: certainties and uncertainties. Eur Heart J. 2014;35:2942-9.

7. Demirag M, Kirali K, Omeroglu SN, Mansuroglu D, Akinci E, Ipek G, et al. Mechanical versus biological valve prosthesis in the mitral position: a 10-year follow up of St. Jude Medical and Biocor valves. J Heart Valve Dis. 2001;10:78-83.

8. Hammond GL, Geha AS, Kopf GS, Hashim SW. Biological versus mechanical valves. Analysis of 1,116 valves inserted in 1,012 adult patients with a 4,818 patient-year and a 5,327 valve-year follow-up. J Thorac Cardiovasc Surg. 1987;93:182-98

9. Tillquist MN, Maddox TM. Cardiac crossroads: deciding between mechanical or bioprosthetic heart valve replacement. Patient Prefer Adherence. 2011;5:91-9.

10. Fino C, lacovoni A, Pibarot P, Pepper JR, Ferrero P, Merlo M, et al. Exercise hemodynamic and functional capacity after mitral valve replacement in patients with ischemic mitral regurgitation: a comparison of mechanical versus biological prostheses. Circ Heart Fail. 2018;11:e004056

11. Kaneko T, Cohn LH, Aranki SF. Tissue valve is the preferred option for patients aged 60 and older. Circulation. 2013;128:1365-71.

12. Poirer NC, Pelletier LC, Pellerin M, Carrier M. 15-year experience with the Carpentier-Edwards pericardial bioprosthesis. Ann Thorac Surg. 1998;66:S57-61.

13. Dellgren G, David TE, Raanani E, Armstrong S, Ivanov J, Rakowski H. Late hemodynamic and clinical outcomes of aortic valve replacement with the Carpentier-Edwards Perimount pericardial bioprosthesis. J Thorac Cardiovasc Surg. 2002;124:146-54.

14. Banbury MK, Cosgrove DM 3rd, White JA, Blackstone EH, Frater RW, Okies JE. Age and valve size effect on the long-term durability of the CarpentierEdwards aortic pericardial bioprosthesis. Ann Thorac Surg. 2001;72:753-7.

15. McClure RS, Narayanasamy N, Wiegerinck E, Lipsitz S, Maloney A, Byrne JG, et al. Late outcomes for aortic valve replacement with the CarpentierEdwards pericardial bioprosthesis: up to 17-year follow-up in 1,000 patients. Ann Thorac Surg. 2010;89:1410-6.

16. Manghelli JL, Carter DI, Khiabani AJ, Gauthier JM, Moon MR, Munfakh NA, et al. A 20-year multicenter analysis of dialysis-dependent patients who had aortic or mitral valve replacement: implications for valve selection. J Thorac Cardiovasc Surg. 2018. https://doi.org/10.1016/j.tcvs.2018.10.168. Epub ahead of print.

17. Hammermeister K, Sethi GK, Henderson WG, Grover FL, Oprian C, Rahimtoola SH. Outcomes 15 years after valve replacement with a mechanical versus a bioprosthetic valve: final report of the veterans affairs randomized trial. J Am Coll Cardiol. 2000;36:1152-8.

18. Rahimtoola SH. Choice of prosthetic heart valve in adults an update. J Am Coll Cardiol. 2010;55:2413-26.

19. de Vincentiis C, Kunkl AB, Trimarchi S, Gagliardotto P, Frigiola A, Menicanti L, et al. Aortic valve replacement in octogenarians: is biologic valve the unique solution? Ann Thorac Surg. 2008;85:1296-301.

20. van Geldorp MW, Eric Jamieson WR, Kappetein AP, Ye J, Fradet GJ, Eijkemans MJ, et al. Patient outcome after aortic valve replacement with a mechanical or biological prosthesis: weighing lifetime anticoagulant-related event risk against reoperation risk. J Thorac Cardiovasc Surg. 2009;137:881-6.

21. Borris LC. Rivaroxaban and dabigatran etexilate: two new oral anticoagulants for extended postoperative prevention of venous thromboembolism after elective total hip arthroplasty. Arch Orthop Trauma Surg. 2010;130:583-9.

\section{Publisher's Note}

Springer Nature remains neutral with regard to jurisdictional claims in published maps and institutional affiliations. 